\title{
Women's Knowledge and Perception of Teratogens and Their Effect in First Trimester of Pregnancy in Antenatal Care Units of Secondary Health Facilities in Kebbi State, Nigeria
}

\author{
Sirajo Mohammed. Sani Ahmad, Jafar Yahaya \\ Department Of Nursing Science, College Of Health Science, \\ Federal University Birnin Kebb, Kebbi State, Nigeria
}

\begin{abstract}
The study was conducted to evaluate the knowledge and perception of teratogens among pregnant women attending antenatal care units in secondary health facility in kebbi state. A descriptive survey design using a probability sampling technique was employed and 120 patients were selected using a questionnaire as an instrument for data collection. The data collected was analyzed using descriptive statistics, the results was presented in frequency distribution tables and percentages. On knowledge and perception of the respondents on teratogens effect, Findings shows that about $48.3 \%$ of the respondents were aware of the teratogens; while about $51.7 \%$ were not aware of the teratogens and their effect. On the substances that are teratogens in nature $35 \%$ said are the most common teratogens,34.2\% of the respondents said dust is the common teratogens they know.meanwhile; $30.8 \%$ of the respondents said alcohol is the dangerous teratogens. It can be noted that majority of the respondents (49.2\%) takes drugs on prescription only. While $24.1 \%$ takes their drugs on non-prescription bases. $13.3 \%$ of the respondent do smokes and also $13.3 \%$ of the respondents keep appointment with A.N.C visits. Also those respondents that visits hospital for any new complains were $17 \%$, while those respondents that use herbal medicine to treat any ailment were $83 \%$.. In conclusion there is no doubt that menace of teratogens effect among pregnant women is increasingly becoming a major public health problem in our society.it was recommended that all pregnant women especially primis should be cautioned extensively about teratogens substances and their consequent effect. This project has shown that the level of knowledge of teratogenic substances and their effect in first trimester of pregnancy is low in secondary health facility in kebbi state.
\end{abstract}

\section{KEY WORDS}

KNOWLEDGE: information or learning gain through experience or education.

PERCEPTION: a way of regarding, understanding or interpreting something.

TERATOGEN: any substance, agent, or process that induces the formation of developmental abnormalities in a fetus.

TRIMESTER: any one of three successive three-month periods into which a pregnancy is divided.

EFFECT: a change which is a result or consequence of an action or other cause.

PREGNANCY: the condition or period of being pregnant.

WOMAN: an adult human female.

DOI: $10.7176 / \mathrm{JHMN} / 82-06$

Publication date: November $30^{\text {th }} 2020$

\section{INTRODUCTION}

\section{BACKGROUND OF THE STUDY}

Teratology is the study of abnormal development in embryos and the causes of congenital malformations or birth defects. These anatomical or structural abnormalities are present at birth although they may not be diagnosed until later in life. They may be visible on the surface of the body or internal to the viscera. Congenital malformations account for approximately $20 \%$ of deaths in the perinatal period. Approximately $3 \%$ of new-born infants will have major malformations and another 3\% will have malformations detected later in life. Bongard (2009).

There are a variety of causes of congenital malformations including:

a) Genetic factors (chromosomal abnormalities as well as single gene defects).

b) Environmental factors (drugs, toxins, infectious etiologies, mechanical forces); and

c) Multifactorial etiologies including a combination of environmental and genetic factors. Briggs, (2009).

More than $90 \%$ of pregnant women take prescription or non-prescription drugs at some time during pregnancy. In general, unless absolutely necessary, drugs should not be used during pregnancy because many of them are harmful to the fetus. Appropriate dispensing is one of the steps for rational drug use; so, it is necessary that drug dispensers should have relevant and updated knowledge and skills regarding drug use in pregnancy. Damase (2009).

After thalidomide had been marketed in the 1960s, people became aware of the teratogenic risk of drug used during pregnancy. Due to this event and several others (diethylstilbestrol in the 70 s and retinoids in the $80 \mathrm{~s}$ ), drug 
prescription for a pregnant woman induces anxiety, not only for woman, but, also for health professionals. However, drug prescription in pregnancy is common. Prescribing or counselling drugs during pregnancy requires health professionals to assess a benefit/risk ratio not only for woman herself but also for her baby. Thus, a right evaluation of the risk is essential. A lack of knowledge of teratogenic or foetotoxic properties of a drug may enhance the risk of neonatal malformation or disease. Conversely, if the risk of malformation is overestimated, this may lead to disadvantageous decisions for the woman and her intended infant. Moreover, previous studies from our group have found differences in the perception of risks according to drugs in a same pharmacological class $^{2}$ or to health professionals, Bongard (2009).

Pregnant women are often faced with complex decisions about whether to undergo medical treatment or continue working in an occupational setting that is permeated with hazardous chemicals. The task for these women is to weigh the benefits of these activities against the potential risks that they may have on the developing embryo. Scientific uncertainty with respect to the teratogenicity of drugs and chemicals in humans leaves health care professionals and their pregnant patients with little predictive information. Cognitive research has shown that it is difficult for people to make complex decisions, particularly when the risks are uncertain. Although the problems inherent in counselling pregnant women regarding teratogenic risk are not new, little time has been devoted to the empiric assessment of how people perceive teratogenic risk and how teratogenic risk information can be best communicated. Briggs, (2009).

\section{LITERATURE REVIEW}

A teratogen is any agent that can induce or increase the incidence of a congenital malformation. Recognition of human teratogens offers the opportunity to prevent exposure at critical periods of development and prevent certain types of congenital malformations. In general, drugs, food additives, and pesticides are tested to determine their teratogenicity to minimize exposure of pregnant women to teratogenic agents. Tyler, (2009).

Teratogenic agents cause approximately $7 \%$ of congenital malformations. A teratogenic agent is a chemical, infectious agent, physical condition, or deficiency that, on fetal exposure, can alter fetal morphology or subsequent function. Teratogenicity depends upon the ability of the agent to cross the placenta. Certain medications such as heparin cannot cross the placenta due to its high molecular weight and are therefore not teratogenic. The embryo is most susceptible to teratogenic agents during periods of rapid differentiation. The stage of development of the embryo determines susceptibility to teratogens. The most critical period in the development of an embryo or in the growth of a particular organ is during the time of most rapid cell division. The critical period for each organ is pictured below. For instance, the critical period for brain growth and development is from three to 16 weeks. However the brain's differentiation continues to extend into infancy. Teratogens can produce mental retardation during both embryonic and fetal periods. Thapar (2010).

\section{TRENDS IN TERATOGENIC EFFECTS HISTORY}

As early as the 17th century, teratology referred to a discourse on prodigies and marvels of anything so extraordinary as to seem abnormal. In the 19th century, it acquired a meaning more closely related to biological deformities, mostly in the field of botany. Currently, its most instrumental meaning is that of the medical study of teratogens, congenital malformations or individuals with significant malformations. There are many pejorative terms that have historically been used to describe individuals with significant physical malformations. The term was popularized in the 1960s by Dr. David W. Smith of the University of Washington Medical School, one of the researchers who became known in 1973 for the discovery of Fetal alcohol syndrome. With greater understanding of the origins of birth defects, the field of teratology now overlaps with other fields of basic science, including developmental biology, embryology, and genetics. Stimmel, (2011).

Studies designed to test the teratogenic potential of environmental agents use animal model systems (e.g., rat, mouse, rabbit, dog, and monkey). Early teratologists exposed pregnant animals to environmental agents and observed the foetuses for gross visceral and skeletal abnormalities. While this is still part of the teratological evaluation procedures today, the field of Teratology is moving to a more molecular level, seeking the mechanism(s) of action by which these agents act. Genetically modified mice are commonly used for this purpose. In addition, pregnancy registries are large, prospective studies that monitor exposures women receive during their pregnancies and record the outcome of their births. These studies provide information about possible risks of medications or other exposures in human pregnancies.

Understanding how a teratogen causes its effect is not only important in preventing congenital abnormalities but also has the potential for developing new therapeutic drugs safe for use with pregnant women, Stimmel, (2011).

The survivors of the atomic bombing of Hiroshima and Nagasaki, who are known as the Hibakusha, were (and still are) victims of severe discrimination due to public ignorance about the consequences of radiation sickness, with much of the public believing it to be hereditary or even contagious. This is despite the fact that no statistically demonstrable increase of birth defects/congenital malformations was found among the later conceived children born to survivors of the nuclear weapons used at Hiroshima and Nagasaki, or found in the later conceived children 
of cancer survivors who had previously received radiotherapy. The surviving women of Hiroshima and Nagasaki who were able to conceive, though exposed to substantial amounts of radiation, went on and had children with no higher incidence of abnormalities/birth defects than in the Japanese population as a whole. Stanwood, (2009).

Since the thalidomide disaster of the late 1950s and early 1960s, pharmacological interventions used to treat women suffering from nausea and vomiting of pregnancy (NVP) have been viewed with great trepidation. As a result, "morning sickness" (as it is most commonly known) has been commonly treated with either dietary or lifestyle changes which have been empirically derived. Effective and safe pharmacological therapies have often been avoided; in fact, Bendectin was actually withdrawn from the world market because of unsubstantiated claims of teratogenicity and the unwillingness of the manufacturer to pay litigation cost, Stimmel, (2011).

\section{CONCEPT OF KNOWLEDGE OF TERATOGENS EFFECT}

Birth defects are known to occur in 3-5\% of all new-borns. They are the leading cause of infant mortality in the United States, accounting for more than $20 \%$ of all infant deaths. Seven to ten percent of all children will require extensive medical care to diagnose or treat a birth defect. And although significant progress has been made in identifying the etiology of some birth defects, approximately $65 \%$ have no known or identifiable cause.

It was previously believed that the mammalian embryo developed in the impervious uterus of the mother, protected from all extrinsic factors. However, after the thalidomide disaster of the $1960 \mathrm{~s}$, it became apparent and more accepted that the developing embryo could be highly vulnerable to certain environmental agents that have negligible or non-toxic effects to adult individuals. Sorokin, (2011).

It is estimated that $10 \%$ of all birth defects are caused by prenatal exposure to a teratogenic agent. These exposures include, but are not limited to, medication or drug exposures, maternal infections and diseases, and environmental and occupational exposures. Teratogen-caused birth defects are potentially preventable. Studies have shown that nearly $50 \%$ of pregnant women have been exposed to at least one medication during gestation. An additional study found that of 200 individuals referred for genetic counselling for a teratogenic exposure, 52\% were exposed to more than one potential teratogen.

Susceptibility to teratogenesis depends on the genotype of the conceptus and the manner in which this interacts with adverse environmental factors. Wilson (2010).

\section{TERATOGENIC AGENTS}

A wide range of different chemicals and environmental factors are suspected or are known to be teratogenic in humans and in animals. A selected few include:

Drugs and medications: alcohol (ethanol), isotretinoin (13-cis-retinoic acid, Roaccutane), temazepam (Restoril; Normisson), nitrazepam (Mogadon), nimetazepam (Ermin), aminopterin or methotrexate, androgenic hormones, busulfan, captopril, enalapril, coumarin, cyclophosphamide, diethylstilbestrol, phenytoin (diphenylhydantoin, Dilantin, Epanutin), Dexamethasone, etretinate, lithium, methimazole, penicillamine, tetracyclines, thalidomide, trimethadione, methoxyethyl ethers, Flusilazole, valproic acid, and many more.

Environmental chemicals: polycyclic aromatic hydrocarbons (polynuclear aromatic hydrocarbons), polychlorinated biphenyls (PCBs), polychlorinated dibenzodioxins a.k.a dioxin, polychlorinated dibenzofurans (PCDFs), hexachlorobenzene hexachlorophene, organic mercury, ethidium bromide, etc. Sorokin, (2011).

Ionizing radiation: atomic weapons fallout (Iodine-131, uranium), background radiation, diagnostic x-rays, radiation therapy[citation needed]

Infections: cytomegalovirus, herpes virus, parvovirus B19, rubella virus (German measles), syphilis, toxoplasmosis, Venezuelan equine encephalitis virus. (An easy way to remember maternal infections is TORCH: Toxoplasmosis, Other agents, Rubella, CMV and HSV.)

Metabolic imbalance: alcoholism, endemic cretinism, diabetes, folic acid deficiency, iodine deficiency, hyperthermia, phenylketonuria, rheumatic disease and congenital heart block, virilizing tumors

The status of some of the above substances (e.g. diphenylhydantoin) is subject to debate, and many other compounds are under varying degrees of suspicion. These include Agent Orange, nicotine, aspirin and other NSAIDs. Other compounds are known as severe teratogens based on veterinary work and animal studies, but aren't listed above because they have not been studied in humans, e.g. cyclopamine. Teratogenic effects also help to determine the pregnancy category assigned by regulatory authorities; in the United States, a pregnancy category of $\mathrm{X}, \mathrm{D}$, or $\mathrm{C}$ may be assigned if teratogenic effects (or other risks in pregnancy) are documented or cannot be excluded.

Isotretinoin (13-cis-retinoic-acid; brand name Roaccutane), which is often used to treat severe acne, is such a strong teratogen that just a single dose taken by a pregnant woman may result in serious birth defects. Because of this effect, most countries have systems in place to ensure that it is not given to pregnant women, and that the patient is aware of how important it is to prevent pregnancy during and at least one month after treatment. Medical guidelines also suggest that pregnant women should limit vitamin A intake to about $700 \mu \mathrm{g} / \mathrm{day}$, as it has teratogenic potential when consumed in excess, Sorokin, (2011). 


\section{TERATOGENESIS}

Susceptibility to teratogenesis varies with the developmental stage at the time of exposure to an adverse influence. There are critical periods of susceptibility to agents and organ systems affected by these agents. Smith, (2011).

Teratogenic agents act in specific ways on developing cells and tissues to initiate sequences of abnormal developmental events.

The access of adverse influences to developing tissues depends on the nature of the influence. Several factors affect the ability of a teratogen to contact a developing conceptus, such as the nature of the agent itself, route and degree of maternal exposure, rate of placental transfer and systemic absorption, and composition of the maternal and embryonic/fetal genotypes. Smith, (2011).

\section{EMPIRICAL REVIEW}

The knowledge and perception of people about teratogens both in developed and developing nations must have contributed to the menace of teratogen effects in the world. The perception of women toward teratogens is still to the large extent negative, most especially in the rural communities. As such high incidence in sub-Saharan Africa remains a major challenge to the maternal and child health programme. Berger, (2011).

The study conducted in Nigeria on the use of herbal medicines among pregnant women has found out that; More than two-third of respondents [67.5\%] had used herbal medicines in crude forms or as pharmaceutical prepackaged dosage forms, with $74.3 \%$ preferring self-prepared formulations. Almost $30 \%$ who were using herbal medicine at the time of the study believed that the use of herbal medicines during pregnancy is safe. Respondents' reasons for taking herbal medications were varied and included reasons such as herbs having better efficacy than conventional medicines [22.4\%], herbs being natural, are safer to use during pregnancy than conventional medicines [21.1\%], low efficacy of conventional medicines [19.7\%], easier access to herbal medicines [11.2\%], traditional and cultural belief in herbal medicines to cure many illnesses [12.5\%], and comparatively low cost of herbal medicines [5.9\%]. Klesges,(2011).

Another study carried-out in Nigeria on the "understanding of the concurrent use of herbal medicine by pregnant women"; over half of the respondents, 56.6\% did not support combining herbal medicines with conventional drugs to forestall drug-herb interaction. About $33.4 \%$ respondents believed herbal medicines possess no adverse effects while 181 [30.4\%] were of the opinion that adverse/side effects of some herbal medicines could be dangerous. Marital status, geopolitical zones, age and educational qualification of respondents had statistically significant effects on respondents' views on the effects of teratogens; while only geopolitical zones and educational qualifications seemed to have influence on respondents' opinion on the harmful effects of herbal medicines to the fetus, Kumar, (2012).

Similar study conducted in Tanzania, by Rashida (2010), “. To assess the knowledge of drug dispensers and pregnant women regarding drug use in pregnancy, focusing on four commonly used drugs that are teratogenic or cause unwanted effects to the fetus and babies "the findings shows that; in total, 200 pregnant women and 200 drugs dispensers were interviewed. Out of 200 drug dispensers, $86(43 \%)$ were willing to dispense artemetherlumefantrine (regardless of the age of pregnancy), 56 (29\%) were willing to dispense sodium valproate, 104 (52\%) were willing to dispense captopril and $50(25 \%)$ were willing to dispense tetracycline. One hundred and thirtythree $(66.5 \%)$ pregnant women reported that they hesitated to take medications without consulting their physicians, $47(23.5 \%)$ indicated that it was safe to take medications during pregnancy, while $123(61.5 \%)$ mentioned that it was best to consult a doctor, while $30(15 \%)$ did not have any preference. Sixty-three $(31.5 \%)$ women reported that they were aware of certain drugs that are contraindicated during pregnancy. It is evident that most drug dispensers have low knowledge regarding the harmful effects of drugs during pregnancy. Drug dispensing personnel should be considered part of the therapeutic chain and, if appropriately trained, they will play a very important role in promoting rational use of medicines.

Also similar study conducted in Ethiopia by Nasir (2009),on" Knowledge, Perception and Drug Consumption Pattern During Pregnancy in Ethiopia "observed that; A total of 224 pregnant women were involved in the study. Out of those, $203(90.6 \%)$ of them have taken NSAIDs since the beginning of their pregnancy. About $201(89.7 \%)$, $198(88.4 \%)$ and $189(84.4 \%)$ of the pregnant women considered that ibuprofen, diclofenac and aspirin are not NSAIDs respectively. Regarding analgesic effect of NSAIDs, 97 (43.3\%) of the pregnant women believed that NSAIDs are effective for treating pain. Acetaminophen was considered as the most effective treatment for pain by $84(37.50 \%)$ of the patients.

A study conducted by Lambers, (2010). Observed that" indiscriminate use of drugs and other harmful chemicals has been on increase in many developing and industrialized countries. It is known that between 65 and $80 \%$ of the world's population use non-prescribed medicines as their primary form of health care. Patients who are likely to be at risk from adverse effects of those medicines include those who are already prone to difficulties from regularly prescribed medications namely fetus, infants and older children, the elderly, as well as pregnant and lactating women. In developing nations most especially, regulation of sales, importation and manufacturing of medicines are not subject to rigorous scrutiny in terms of safety and efficacy as is the case for conventional 
western/allopathic medicines.

\section{THEORETICAL FRAMEWORK}

To study pregnant women's knowledge and perception of teratogen effect, a comprehensive theoretical model is used which is depicted in figure below. The model integrates constructs from two main theoretical models in health psychology, specifically the health belief model (HBMO (Rosenstock, 2009) and the theory of planned behaviour (TPB) (Ajzen, 2009), which are widely used to investigate the knowledge behaviour. We added to these psychological constructs, factors related to health care system example access, pathways, and doctor-patient interaction. Based on social cognitive psychology, the health belief model and the theory of planned behaviour provide frameworks to change behaviour by addressing the individual's belief, subjective norms and perception of control risk. The underlined assumption of these models is that inducing individual behaviour change requires more than the provision of knowledge alone. The health belief model synthesises the effect depend on a specific set of knowledge, as well as specific set of interpretation of danger and risk. When individual fail to perceive appropriate levels severity and susceptibility, it becomes the public health educator's responsibility to elucidate the risk. While the health belief model explores the motivators for action, the theory of planned behaviour, synthesises belief, social norms and perceived control to acquire behaviour change. This conceptual frameworks is apply in this study because they assumed that factors affecting health behaviours might be culturally influenced example belief and norms but because they also allow us to predict the determinants of knowledge and perception pattern in the communities.

To understand how the health system works for implementing increased knowledge on teratogens effect, we integrates various mechanisms, functions and links, infrastructure and human resources, access and quality of services, information and communication system and opportunity for changes. Health care providers play an important role in teratogens effect prevention by providing information and services. Action taken by them is likely to be shaped not only by professional regulations, but also by their knowledge and perception towards teratogens effect and women's role in prevention. Such perception and knowledge are relevant to the potential impact that health care providers can have in changing preventive practices among pregnant women.

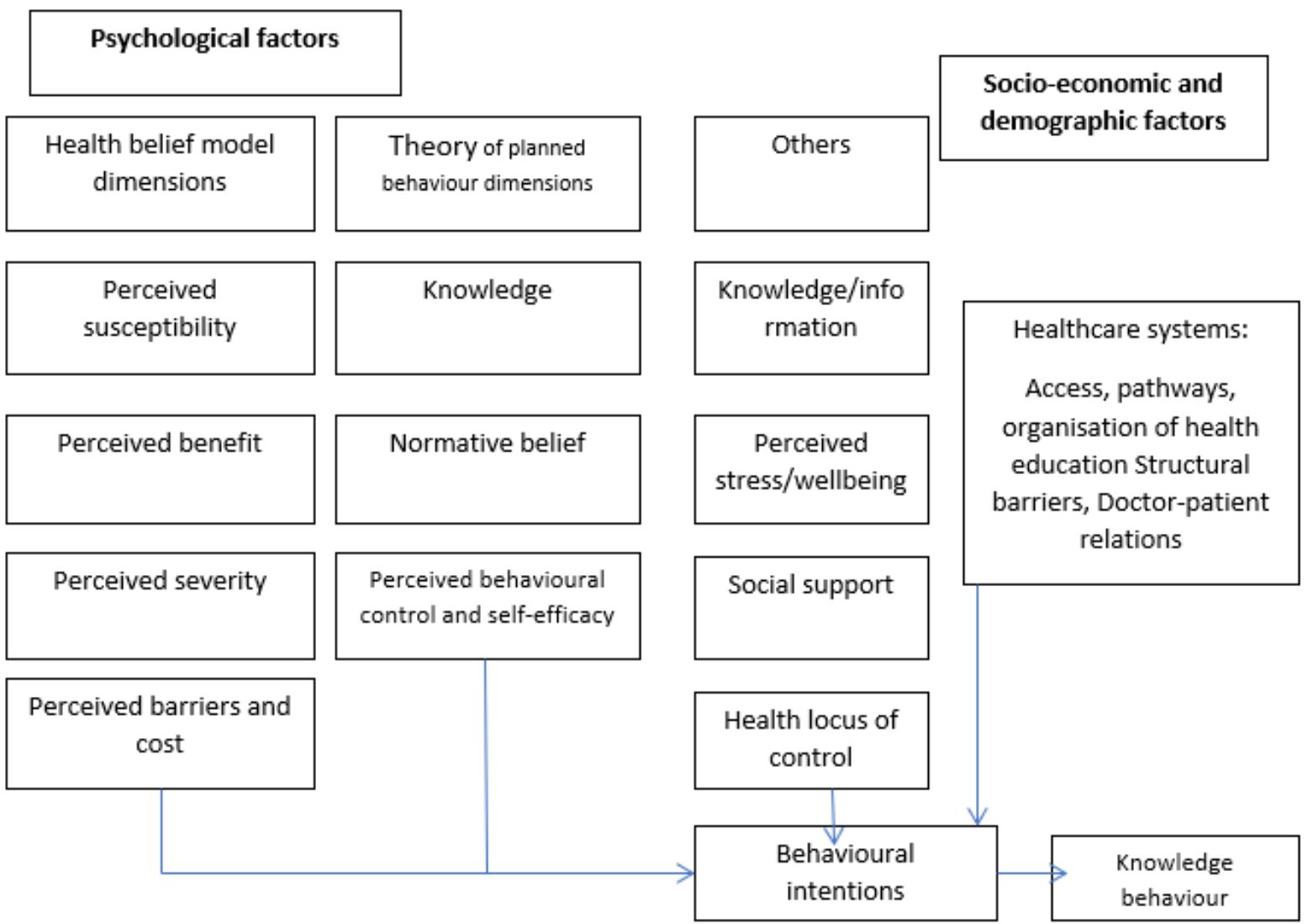

\section{STATEMENT OF THE PROBLEM}

Teratogens are toxic agents that cause abnormal development resulting in birth defects. An estimated 500,000 new cases and 250,000 prenatal deaths occur worldwide annually with vast majority (80\%) of these in developing countries, W.H.O (2009). 
Between $3 \%$ and $5 \%$ of children born in the United States are born with developmental defects. Of these, only $2 \%$ to $3 \%$ of them are classified as teratogen-induced malformations. However, $60-70 \%$ of all defects are of unknown origin--developmental toxicology is an expanding field and some of the unclassified defects may eventually be classified as teratogen-induced. Teratogenic substances do not affect each developing fetus in the same way. The fetus is most at risk during organogenesis (development of organs), which begins at about three weeks post-conception, and continues until the organs' defining characteristics have been achieved. The severity and type of the congenital malformation may vary with the duration of exposure and the specific teratogen. However, exposure to the same substance on different days in development can produce different defects. Many teratogens are fatal at high doses, causing miscarriage. Defects that present later, such as growth development and functional impairment, are harder to relate to teratogen exposure. In the time between birth and detection of impairment, exposure to other toxicants may have occurred, increasing the difficulty of identifying the responsible toxicant, W.H.O (2009).

Nwoke (2009) observed that in Nigeria many women of childbearing age use more of the following teratogenic agents; alcohol, cocaine, marijuana or nicotine. $15 \%$ of these women use drugs with sufficient frequency to cause damage to a fetus during pregnancy. Statistic showed that 30 to $40 \%$ of pregnant women smoke, 60 to $90 \%$ use analgesic during pregnancy, 20 to $30 \%$ use sedative and an undetermined number continue to use illicit drugs. Dacey and Travers (2002), observed that a number of women continue to use drugs before they realize they are pregnant.

According to W.H.O (2009), deformed babies are born, showing the damage drugs can be on a developing fetus. For instance, the thalidomide tragedy in the early 1960s awakened the medical professions and the public alike to the potential dangers of drugs for pregnant women. It was stated that pregnant women took the popular tranquilizer thalidomide as a sleeping pill and an antinausea measure that produced no adverse reactions in the women, but physicians discovered a sizable increase in children born with either partial or no limbs. In some cases, feet and hands were directly attached to the body. At other times the outcomes were dumbness, deafness blindness and mental retardation these conditions are devastating.

Based on my own personal experience (person carrying-out this study) most of the women in Hausa community continue to takes some drugs before they realize they are pregnant; they also indiscrinately takes traditional herbs and concussion with a view to enhance their husband's sexual satisfaction.

This study is aimed at assessing the knowledge and perception of women attending secondary health care facilities in Kebbi state; toward effects of teratogens considering the fact that; some women may be pregnant while having medical conditions requiring intervention.

\section{AIMS AND OBJECTIVES OF THE STUDY}

This study is aimed at assessing the knowledge and perception of women attending secondary health institution in Kebbi state; toward effects of teratogens in first trimester of pregnancy.

\section{OBJECTIVES OF THE STUDY}

$>$ To assess the level of knowledge on teratogens among pregnant women attending ante-natal care unit of secondary health facilities in Kebbi state.

$>$ To determine the perception of various stages/levels of pregnancy and consequences of indiscriminate use of drugs among pregnant women attending ante-natal care unit of secondary health institution in Kebbi state.

$>$ To ascertain the level of compliance on the advice by health professionals regarding use of herbal medicines and other precautionary measures in first trimester among respondents.

\section{RESEARCH QUESTIONS}

* What is the level of knowledge of the respondents on teratogen effect in first trimester of pregnancy?

* How do the respondents perceive various stages/levels of pregnancy and consequences of indiscriminate use of drugs?

* Do the respondents comply with advice given by the health care professionals?

\section{RESEARCH METHODOLOGY}

\section{RESEARCH DESIGN}

This study is cross-sectional descriptive survey design because it involves the single examination of a cross-section of a target population at a given point in time.using a detailed questionnaire for assessment of their knowledge, perception, behavior and practice in relation to teratogens and their effect.

\section{POPULALATION OF THE STUDY (TARGET POPULATION)}

The population of this study consisted of all pregnant women attending ante-natal care unit of secondary health 
facility in kebbi state, which spreads from tuesday to Friday (4 days). Making a total of 300 pregnant women

\section{SAMPLING TECHNIQUE}

A total population of four days was picked which is 300 pregnant women to represent the population. Acccording to Nwana(2009), if a population is a few hundred then $40 \%$ or more will be sufficient to represent the total population.

Therefore $40 \%$ of 300

40x 300

100

$=40 \times 3$

$=120$

Therefore 120 questionnaires were distributed among the respondents; attending the antenatal care clinic of secondary health facility in kebbi state, 30 questionnaires were distributed on each day of the four days period of data collection.

\section{INSTRUMENT FOR DATA COLLECTION}

Data was collected with the aid of questionnaire to evaluate the pregnant women,s knowledge on teratogens effect in first trimester of pregnancy, perception of various levels of pregnancy, as well as level of compliance on the advice given by health care professionals.

\section{VALIDITY OF INSTRUMENT}

The questionnaire was validated using content validity where it was given to the project supervisor to ascertain its validity.

\section{RELIABILITY OF INSTRUMENT}

The instrument used for this study was reliable to the study; because the questions used by the researcher in collecting the data from the respondents were constructed in a simple and unambiguous word for easy understanding.

\section{TECHNIQUE OF DATA ANALYSIS}

The data was analysed using descriptive statistical measures; the statistical method to be used is frequency distribution tables.

\section{ETHICAL CONSIDERATION}

Official approval was sought from the head of the department, nursing sciences before administering questionnaire to the population concern. Meanwhile confidentiality of respondents were strictly ensured and informed of their right to withdraw their participation in the study at any age.

\section{DATA PRESENTATION AND ANALYSIS}

Data was collected through a self-administered questionnaire to the patients attending Antenatal unit of secondary health facility in kebbi state. Using a frequency distribution tables to presents the characteristics of the studied patient's population. A total of 120 questionnaires were distributed and retrieved. 
TABLE 4.2 SOCIO-DEMOGRAPHIC DATA OF THE RESPONDENTS

\begin{tabular}{|l|l|l|}
\hline Variables & Frequency & Percentage (\%) \\
\hline Age in years distribution & & \\
$12-17$ & 0 & $0 \%$ \\
$18-28$ & 25 & $20.8 \%$ \\
$29-39$ & 35 & $29.2 \%$ \\
$40-49$ & 60 & $50 \%$ \\
\hline Total & $\mathbf{1 2 0}$ & $\mathbf{1 0 0} \%$ \\
\hline Marital status & & \\
married & 59 & $49.2 \%$ \\
divorcee & 35 & 29.2 \\
widow & 25 & $20.8 \%$ \\
single & 1 & $0.8 \%$ \\
\hline Total & $\mathbf{1 2 0}$ & $\mathbf{1 0 0} \%$ \\
\hline Occupation & & \\
civil service & 82 & $15 \%$ \\
full-house-wife & 20 & $68.3 \%$ \\
trading/house-wife & 18 & $16.7 \%$ \\
\hline Total & $\mathbf{1 2 0}$ & $\mathbf{1 0 0} \%$ \\
\hline
\end{tabular}

Table 4.2 above age distribution of variables shows that; majority of the respondents $50 \%$ falls within the age range of 40-49 years. This is followed by the age range of 29-39 (29.2\%). 20.8\% falls in the range of 18-28; respectively.

Marital status variables above show that; the majority of the respondents (49.2\%) are married; this is followed by $29.2 \%$ that are divorcee respondents.

Occupation distribution variable above shows that; the majority of the respondents $(68.3 \%)$ were full housewife; this is followed by the $16.7 \%$ that belongs to trading/house-wife, then $15 \%$ were civil servants respectively. Table 4.3 level of knowledge and perception about teratogens and their effect

\begin{tabular}{|l|l|l|}
\hline Variables & Frequency & Percentage (\%) \\
\hline Have you ever heard of teratogens? & & \\
Yes & 58 & $48.3 \%$ \\
No & 62 & $51.7 \%$ \\
\hline Total & 120 & $100 \%$ \\
\hline Awareness on the symptoms of & & \\
teratogens. & 49 & $40.8 \%$ \\
-Death & 30 & $25 \%$ \\
-malformation & 41 & $34.2 \%$ \\
-severe pain & 120 & $100 \%$ \\
\hline Total & & \\
\hline Knowledge on whether teratogens & & \\
effect is preventable. & 62 & $51.7 \%$ \\
-No & 58 & $48.3 \%$ \\
-Yes & 120 & $100 \%$ \\
\hline Total & & \\
\hline Awareness on whether teratogens & 32 & $26.6 \%$ \\
effect is curable or not. & 38 & $31.7 \%$ \\
-No & 50 & $41.7 \%$ \\
\hline -Yes & 120 & $100 \%$ \\
\hline -I don't know & & \\
\hline Total & & \\
\hline
\end{tabular}

The table above shows that about $48.3 \%$ of the respondents were aware of the teratogens; while about $51.7 \%$ are not aware of the teratogens and their effect. 
Table 4.4 Level of perception of teratogens and stage of pregnancy they are likely to cause harm

\begin{tabular}{|l|l|l|}
\hline At what stage of pregnancy the fetus is vulnerable to teratogens effect & Frequency & Percentage (\%) \\
\hline First trimester & 17 & $14.2 \%$ \\
\hline Second trimester & 24 & $20 \%$ \\
\hline Third trimester & 30 & $25 \%$ \\
\hline At term & 49 & $40.8 \%$ \\
\hline Total & 120 & $100 \%$ \\
\hline Which of those substances is teratogens in nature & Frequency & Percentage $\%$ \\
\hline Dust & 42 & $35 \%$ \\
\hline Alcohol & 37 & $30.8 \%$ \\
\hline Fruits & 41 & $34.2 \%$ \\
\hline Total & 120 & $100 \%$ \\
\hline
\end{tabular}

On the table above majority of the respondents $40.8 \%$ said period at term is the most critical in which fetus is vulnerable to teratogens effect, followed by $25 \%$ who said third trimester then $20 \%$ who said second semester, while the least $14.2 \%$ said first trimester is the critical period.

On the substances that are teratogens in nature $35 \%$ said dust are the most common teratogens, $34.2 \%$ of the respondents said fruits is the common teratogens they know.meanwhile; $30.8 \%$ of the respondents said alcohol is the dangerous teratogens.

Table 4.5:level of compliance regarding taking of drugs on prescription and advice given by the health care professionals

\begin{tabular}{|l|l|l|}
\hline Variables & Frequency & Percentage $\%$ \\
\hline Taking of drugs on prescription & 59 & $49.2 \%$ \\
\hline Taking of drugs on the bases of self-prescription & 29 & $24.1 \%$ \\
\hline Smoking & 16 & $13.3 \%$ \\
\hline Keeping appointment with A.N.C visits & 16 & $13.3 \%$ \\
\hline Total & 120 & $100 \%$ \\
\hline
\end{tabular}

From the table above, it can be noted that majority of the respondents $(49.2 \%)$ takes drugs on prescription only. While $24.1 \%$ takes their drugs on non-prescription bases. $13.3 \%$ of the respondent do smokes and also $13.3 \%$ of the respondents keep appointment with A.N.C visits.

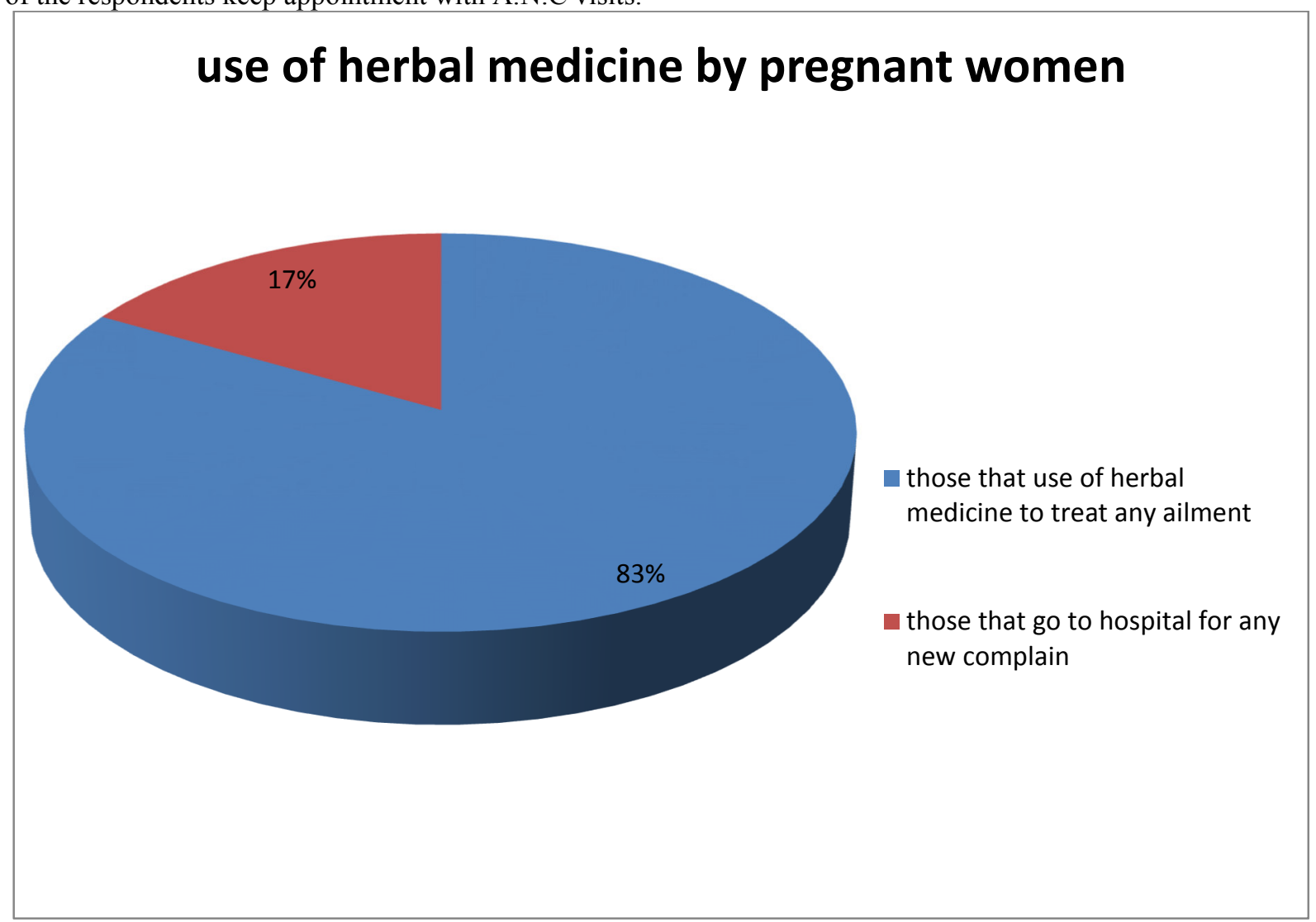

FIGURE 4.6: USE OF THE HERBAL MEDICINE BY THE RESPONDENTS 
From the figure above those respondents that visits hospital for any new complain are $17 \%$, while those respondents that use herbal medicine to treat any ailment were $83 \%$.

\section{DISCUSSION OF FINDINGS}

\section{Socio-demographic data of the respondents}

The result from socio-demographic variables of the respondents showed that; majority of the respondents $50 \%$ falls within the age range of 40-49 years. This is followed by the age range of $29-39(29.2 \%) .20 .8 \%$ falls in the range of 18-28; respectively.

Marital status variables above show that; the majority of the respondents (49.2\%) are married; this is followed by $29.2 \%$ that are divorcee respondents.

Occupation distribution variable above shows that; the majority of the respondents $(68.3 \%)$ were full housewife; this is followed by the $16.7 \%$ that belongs to trading/house-wife, then $15 \%$ were civil servants respectively.

The above findings is comparable with findings made by Kumar (2012) who found out that; Marital status, geopolitical zones, age and educational qualification had statistically significant effects on respondents views on the effects of teratogens.

\section{Level of knowledge of the respondents on teratogens}

Findings shows that about $48.3 \%$ of the respondents were aware of the teratogens; while about $51.7 \%$ were not aware of the teratogens and their effect.

On the substances that are teratogens in nature $35 \%$ said dust are the most common teratogens, $34.2 \%$ of the respondents said dust is the common teratogens they know.meanwhile;30.8\% of the respondents said alcohol is the dangerous teratogens

This findings is comparable with findings in a study carried out by Berger, (2011).who found out that; the knowledge and perception of people about teratogens both in developed and developing nations must have contributed to the increased menace of teratogen effects in the world.

Level of perception of teratogens and stage of pregnancy they are likely to cause harm

Majority of the respondents $40.8 \%$ said period at term is the most critical in which fetus is vulnerable to teratogens effect, followed by $25 \%$ who said third trimester then $20 \%$ who said second semester, while the least $14.2 \%$ said first trimester is the critical period.

On the substances that are teratogens in nature $35 \%$ said dust are the most common teratogens, $34.2 \%$ of the respondents said fruits is the common teratogens they know.meanwhile;30.8\% of the respondents said alcohol is the dangerous teratogens.

This findings correlates with that of W.H.O (2009), in Africa which found out that" The perception of women toward teratogens is still to the large extent negative, most especially in the rural communities. As such high incidence in sub-Saharan Africa remains a major challenge to the maternal and child health programme".

Levels of compliance on the advice by health professionals regarding use of herbal medicines and consequences of indiscriminate use of drugs in the first trimester

It can be noted that majority of the respondents (49.2\%) takes drugs on prescription only. While $24.1 \%$ takes their drugs on non-prescription bases. $13.3 \%$ of the respondent do smokes and also $13.3 \%$ of the respondents keep appointment with A.N.C visits.

Also those respondents that visits hospital for any new complains are $17 \%$, while those respondents that use herbal medicine to treat any ailment were $83 \%$.

Similarly a study conducted by Lambers, (2010). Observed that" indiscriminate use of drugs and other harmful chemicals has been on increase in many developing and industrialized countries. It is known that between 65 and $80 \%$ of the world's population use non-prescribed medicines as their primary form of health care. Patients who are likely to be at risk from adverse effects of those medicines include those who are already prone to difficulties from regularly prescribed medications namely fetus, infants and older children, the elderly, as well as pregnant and lactating women. In developing nations most especially, regulation of sales, importation and manufacturing of medicines are not subject to rigorous scrutiny in terms of safety and efficacy as is the case for conventional western/allopathic medicines.

Another study carried-out in Nigeria by Kumar (2012) on the "understanding of the concurrent use of herbal medicine by pregnant women"; over half of the respondents, $56.6 \%$ did not support combining herbal medicines with conventional drugs to forestall drug-herb interaction. About 33.4\% respondents believed herbal medicines possess no adverse effects while 181 [30.4\%] were of the opinion that adverse/side effects of some herbal medicines could be dangerous.

\section{CONCLUSION}

There is no doubt that menace of teratogens effect among pregnant women is increasingly becoming a major public health problem and a source of worry in the maternal and child health sector in our society. This is because; it causes so many effects such as congenital malformations that cannot be easily treated when the baby is born. 
Therefore, more research are needed to explore awareness on the dangers about teratogenic effect on pregnancy.

\section{REFERENCES}

Addis, A., Magrini, N. \&Mastroiaco, p. (2010).Drug use during pregnancy.Lancet, 357,800

Aguwa, C.N, \&Ogbuokua J.E (2010).Handbook of Pharmacology for Nursing and Allied Health Professions. Enugu: Africana Publishers Ltd.

Ajzen.mRosenstock. N( 2009), Conceptual Issues in behavioural determining long-term sequel of prenatal teratogens exposure. Journal of women Psychology and Psychiatries, 43, 81-102.

Andrade, S. E. Gurwitz, J.H. Davis, R.L, Chan, K.A, Frinkelstein, J.A., Fortman, K. Mcphillips, H; Raebel, M.A.; Roblin, D. Smith, D.H' Yood, M.U.; Morse A.N. \& Platt. R. (2009).Prescription drug use in Pregnancy. American Journal of Obstetrics and Gyneocology191, 398-407.

Altman, L. (2011). High HIV Levels raise risks to new bons New York Times. August 17.

Arthur, C.C. \& Hall J.E. (2011).Text book of Medical Physiology. Mississippi: Guyton \& Hall.

Ashmead, G.G. (2009). Smoking and Pregnancy. Journal of Maternal, Fetal and Neonatal Medicine, 14, $297-304$.

Baklinski, T.M. (2008). Death of unborn Child as a result of Mother's Drug use: A Homicide www. Tyesitenews.com. lifesitenew.

Berger, K.S. \& Thompson, R.A. (2011).The Developing Person, Through life Span. New York. Work Publishers.

Blackman, J. (2010). Medial Aspects of Developmental Disabilities in Children Birth to three, Gaithersburg.M.D. Aspen Publications.

Bongard V, Ménard-Taché S, Bagheri H, Kabiri K, Lapeyre-Mestre M, Montastruc JL. (2009)Perception of the risk of adverse drug reactions : differences between health professionals and non health professionals. Br $\mathrm{J}$ Clin Pharmacol.;54:433-6.

Briggs GG, Freeman RK, Yaffe SJ.( 2009). Drugs in pregnancy and lactation: a reference guide for fetal and neonatal risk, 6th Edition, Lippincott Williams and Wilkins eds, Baltimore.

Byer, C.O. \&Shainberg L.W. (2009). Dimension of Human Sexuality (3rd ed.) Dubuque, 1A Brown \& Bench Mark.

Bookstein, F.L; Streight; A.P; Sampson, P.D; Conner, P.D; \& Barr, H.M. (2012).Corpus Callosum Shape and Neurological Deficits in Adult Males with Heavy Fetal Alcohol exposure.Neuroimage' 15,233-251.

Caldwell, M.B. \& Rogers, M.F. (2010).Epidemiology of Pediatric HIV Infection.Pediatric Clinics of North Amercia, 38, 1-16.

Cnattingius S.; Signorello, L.B. Anneren, G; Rane, A. Granatn.F. (2009).Caffeine in take and risk of first-trimester Spontaneous Abortion New England Journal of Mdicine342, 1839-1845.

Crandal, C. Croby, R.D., \& Carlson, G.A. (2009). Does Pregnancy affect Outcome of Methadone Maintenance Treatment: Journal of Substance Abuse treatment 26,295-303.

Dacey J.S. \& Travers J.F (2011).Human Development Across the Lifespan. New York, McGraw Hill.

Damase-Michel C, Vié C, Lacroix I, Lapeyre-Mestre M, Montastruc JL (2009);. Drug counselling in pregnancy: an opinion survey of French community pharmacists. Pharmacoepidemiol Drug Saf. 13:711-5.

Dreotsi, I (2012).Nutritional Factors Underlying the Expression of the Fetal Alcohol Syndrome. Ann. NY, Acad. Sci. (678 193-204.

Eskenazi, B. Staplton, A.L, Kharrazi, M. \&Chee, W.Y (2011).Associations between Maternal Decaffeinated and Caffeinated Coffee Consumption and fetal growth and gestational duration.Expidemology, 10, 242-249.

Fernande, S. O. Sabharwal, M. Simley, T. Pastszak, A. Koren, G \&Einarson T. (2010). Moderate to heavy Caffeine Consumption During Pregnancy and Relationship to Spontaneous Abortion and AbornmalFetal growth: A Meta Analysis. Reproductive Toxicology: 12, 433-444. 6

Fried, P.A. \& Watkinson, B. (2010). 36- and 48 month Neurobehavioural follow-up of children prenatally exposed to marijuana, cigarette and alcohol. Development and Behavioural Pediatrics11, 49-58.

Fried, P.A. (2011). Conceptual Issues in behavioural determining long-term sequel of prenatal marijuana exposure. Journal of Child Psychology and Psychiatries, 43, 81-102.

Haustein, K.O. (1999). Cigarette Smoking, Nicotine and Pregnancy.Int.J. Clin. Pharmacol.Ther.37.417-427.

Hulse, G.K' O’Neill, Pereira, C. \& Brewer, C, (2009). Obstetric and Neonatal outcomes Associated with Maternal Natrexone Exposure. Auatralian and New Zealand Journal of Obstetrics and Gyneocology, 41,424-428.

Kallen, B. (2010). Neonate Characteristics after Maternal use of Antidepressants in late pregnancy. Achieves of Pediatric and Adolescent Medicine, 158, 312-312-316.

Kumar.S. (2012).Fetal Alcohol Syndrome: Mechanism of Spermatogenesis. Ann. Chin. Lab. Sci. 12, $254-257$.

Klesges, L.M. Johnson, K.C, Ward. K. D \& Barnard, M. (2011). Smoking Cessation in pregnant in pregnant Women. Obstetricks and Gynecological Clinics of clinics of North America 28, 269-282.

Lambers, D.S. \& Clarke K. E. (2010).The Maternal and Fetal Physiologic Effects of Nicotine, Serine Perinatol. $20115-126$

Lancaster, S. (2010). Community Health Nursing: Process and Practice for Promoting Health. Lexington: Mosley 
year Book

Lewis, M. W. Misra, S. Johnson, H.L, \& Rosen, T.S, (2009). Neurological and Developmental outcome of Prenatally Cocaine-exposed offspring from 12-13 weeks.

Little, G.A. (2010).The Fetus at Risk.In R.A. Hoe-Kelman, \& B. Friedman, N.M. Nelson, \& H.M. Seidel (Eds).Primary Pediatric care (2nd eds.) St. Louis: Mosley Yearbook.

Mathews, T.J Menacker, F. \&MacDorman M.F. (2009), Infant mortality Statistics from the 2001 Period Linked birth/infant death data set. National Vital Statistics reported, 52, 1-28.

Miller, M.E. (2010). Genetic Disease. In R.A hoekelman (Ed.) Primary Pediatric care (2nd ed.) St. Louis Moshy Year Book.

Moore, K \&Persaud, T. (2010).Before we are born: Essentials of Embryology and birth defects.Philadelphia Saunders.

Moran.B. (2009).Maternal Infections.In S. Mattson and J. Smith (Eds.).Core Curriculum for Maternal-newborn nursing, Philadelphia.W.B. Sounders.

Nasir T, Damase-Michel C, Christaud J, Berrebi A, Lacroix I, Montastruc JL,(2009). What do pregnant women know about non-steroidal anti-inflammatory drugs? Pharmacoepidemiol Drug Saf.;18:1034-8.

Nwana, O.C. (2000). Evaluation of school and College Examinations in the Nigerian Education System.InFafunwa, A.B.,(ed) Educational Foundation. Ibadan: Wemilore Press (Nig) Ltd.

Nwana, O.C. (2009). Introduction to educational research.Ibadan: Heinemann Educational Books (Nigeria) PLC.

National Drug Enforcement Agency (2010).2003 Drug data Collection and report.Ikoyi, Lagos, Drug Demand Reduction Directorate National Drug Enforcement Agency.

Obot, I.S. (2010). Epidemiology and Control of Subatance Abuse in Nigeria.Centre for Research and Information on Substance Abuse (CRISA). Jos Nigeria

Oladele, J.O, Rosenstock g. Ajzen u,(2009). Fundamentals of Psychological Foundations of Education. Lagos Johns-Lad Publishers Ltd.

Olds S. London M. \&Ladweig.P (2010).Maternal; Unborn Reading M.A. Addison-Wesley.

O’ Leary, C. (2009).Fetal Alcohol Syndrome.Journal of Pediatric Child Health 40, 2-7.

Preston, A.M. (2010). Cigarette Smoking Nutritional Implications.Prog.Food Nutr. Sci. 15, 183-217.

Rashida.j.Lacroix I, Damase-Michel C, Lapeyre-Mestre M, Montastruc JL. Prescription of drugs during pregnancy in tanzania. Lancet 2010;256:1735-6.

Richardson, G.A.C, Willford, J., Day. N. L, \&Goldschniidt, L. (2009). Prenatal alcohol \& Marijuana Exposure.Effects on Neuropsychological outcome at 10 years.Neurotoxicology and Teratology, 24, 309-320.

Rodier, P. M (2009).Environmental Causes of Central Nervous System Maldevelopment.Pediatrics, 113,10761083.

Santrock, J.W. (2010). Life Span Development Texes, Brown \& Bench Mark.

Santrock, J.W. (2008). Life Span Development New Yorks.McGeaw hill Companies Inc.

Sawnani, H., Jackson, T. Murphy, T. Beckerman, R. \&Simakajornboon, n. (2010). The Effect of Maternal Smoking on Respiratory and arousal. Patterns in Preterm infants during sleep.American Journal of Respiratory \& Critical Care medicine, 169, 733-738.

Smith, L. Muir, D.W, \&Kisilevsky, B. (2011). Preterm infants responses to auditory stimulation of varying intensity. Paper Presented at the meeting of the Society for Research in Child Development. Minneapolis.

Sorokin, P. (2011).New agents \& future directions in biotherapy.Clinical Journal of Oncological Nursing, 6, 19-24.

Stanwood, G.D \& Levitt, P.(2009).Drug Exposure Early in life Functional repercussions of changing neuropharmacology during sensitive Periods of Brain development.Current Opinions in Pharmacology 4, 6571.

Stimmel, B. (2011). The fact about drug use. New York: Consumer Report Books.

Stocks, J. \&Dezatenx, C. (2009).The effects of Parental Smoking on lung function and development during infancy.Respirology; 8, 266-285.

Thapar, A, Fonler, T, Rice F, Scairfield, J, Van, Den Breed, Thomas, S. Harold, G \& Hay D, (2010). Maternal Smoking during Pregnancy and attention deficit hyperactivity disorder, symptom in offspring American Journal of Psychiatry, 160, 1985-1989.

World Health Organisation :Traditional medicine.

[http://www.who.int/mediacentre/factsheets/fs134/en/] webciteFact sheet Number 134

Accessed on $15^{\text {th }}$ july, 2013

Wilson.jimMazzota P, Magee LA, Maltepe C, Lifshitz A, Navioz Y, Koren G.( 2009), the perception of teratogenic risk by women with nausea and vomiting of pregnancy.Principle of teratology; journal on monograph Environment and Birth Defects. Review, 22(5):153 - 165.Reprod Toxicol.;13:313-9.

Tyler, K. A. \& Johnson K.A (2009), Pathways in and out of substance use among homeless-emerging adults. Journal of Adolescent Research. 21 (2), 133-157.

Zanden, V. (1993).Human Development. New York. McGraw-Hill Inc. 